\title{
Decreased exhaled nitric oxide in subjects with HIV infection
}

\author{
Mark O Loveless, Charles R Phillips, George D Giraud, William E Holden
}

\begin{abstract}
Background-Nitric oxide (NO) may be an important component of the host defence against infections. Endogenously produced NO is present in exhaled air and may be representative of respiratory tract production of NO. Since subjects infected with HIV are prone to develop respiratory infections, it was postulated that exhaled NO might be reduced in such individuals. Methods - The exhaled concentration of NO (n1/1) and minute ventilation (1/min) were measured and exhaled NO release (nl/ $\mathrm{min} / \mathrm{m}^{2}$ ) calculated in 36 subjects infected with HIV (20 non-smokers, 16 smokers) and 31 non-smoking subjects with no active medical conditions.

Results - Exhaled NO from HIV positive individuals was less than from control subjects of similar age, height, and weight. Cigarette smoking did not account for the decreased exhaled NO in HIV positive individuals as both smoking and non-smoking HIV positive subjects had decreased exhaled NO compared with control subjects.

Conclusion - Exhaled NO is decreased in subjects infected with the HIV. Since NO functions in host defence against bacterial, viral, and fungal infections, reduced exhaled NO may indicate a mechanism of impaired host defence in HIV infection. (Thorax 1997;52:185-186)
\end{abstract}

Keywords: nitric oxide, human immunodeficiency virus.

Department of Medicine, Oregon Health Sciences University and Medical Service, Portland VA Medical Center, Portland, Oregon 97201, USA

M O Loveless

C R Phillips

G D Giraud

W E Holden

Correspondence to:

Dr W E Holden.

Received 19 February 1996

Returned to authors

8 May 1996

Revised version received

10 July 1996

Accepted for publication

12 August 1996
Nitric oxide (NO) may participate in defence against viral, bacterial, fungal, and protozoal infections. ${ }^{1}$ Such infections occur with increased frequency in individuals infected with the human immunodeficiency virus (HIV). Endogenously produced NO is present in the exhaled air of normal humans ${ }^{2}$ and exhaled $\mathrm{NO}$ is increased in inflammatory lung diseases such as asthma, ${ }^{34}$ bronchiectasis, ${ }^{5}$ and viral infections. ${ }^{6}$ Treatment of asthmatic subjects with corticosteroids reduces exhaled NO. ${ }^{7}$ Exhaled NO is also reduced in cigarette smokers, ${ }^{3}$ a population susceptible to respiratory infections. Since HIV positive individuals are at risk for respiratory tract infections, we postulated that exhaled NO might be reduced in these subjects.

\section{Methods}

We measured NO in the exhaled air of 36 HIV positive subjects (34 men; 20 non-smokers) recruited from an ambulatory care centre and 31 healthy non-smoking control subjects (23 men). The control subjects were recruited from hospital colleagues and coworkers, had no risk factors for HIV infection, and were taking no prescription medications. The most recent CD4 lymphocyte count for each HIV positive subject was recorded. Ten of the HIV positive subjects were receiving trimethoprim-sulphamethoxazole as prophylaxis against Pneumocystis carinii infection and none were receiving corticosteroids. Control subjects and HIV positive subjects were similar in terms of age (35.7 (1.8) versus 37.8 (1.4) years), height (5.9 (0.1) versus 5.8 (0.1) feet), and weight (163 (7) versus 167 (5) pounds).

Supine subjects breathed through a two way valve and mouthpiece with nose clips in place for five minutes. The inhalation port of the mouthpiece was connected to a compressed air source $(\mathrm{NO}<1 \mathrm{ppb})$ and the exhalation port was connected to a mylar collection bag. The concentration of $\mathrm{NO}$ in the collection bag was measured by chemiluminescence (Sievers, 270B, Boulder, Colorado, USA) and the volume of the bag was measured in a Tissot gasometer. Exhaled NO (nl/min) was calculated as the product of NO concentration (nl/1 or $\mathrm{ppb})$ and minute ventilation $(1 / \mathrm{min})$. In healthy subjects exhaled NO is proportional to body surface area (unpublished observations) so we expressed exhaled NO per $\mathrm{m}^{2}$.

Comparisons between groups were made using unpaired Student's $t$ tests with $\mathrm{p}<0.05$ being considered significant.

\section{Results}

The amount of exhaled NO from HIV positive subjects (39 (3) $\mathrm{nl} / \mathrm{min} / \mathrm{m}^{2}$ ) was less than that from the control subjects (57 (6) $\mathrm{nl} / \mathrm{min} / \mathrm{m}^{2}$; $\mathrm{p}<0.001)$. The reduction in exhaled $\mathrm{NO}$ in HIV positive subjects was present in both smokers (42 (5) $\mathrm{nl} / \mathrm{min} / \mathrm{m}^{2} ; \mathrm{p}<0.03$ ) and nonsmokers ( 37 (3) $\mathrm{nl} / \mathrm{min} / \mathrm{m}^{2} ; \mathrm{p}<0.008$; fig 1). The distribution of CD4 lymphocyte counts in HIV positive subjects was $207(34) / \mathrm{mm}^{3}$ with 19 of 36 having a count of less than $200 / \mathrm{mm}^{3}$. Four of the subjects with less than $200 / \mathrm{mm}^{3}$ CD4 lymphocytes had a history of prior AIDS 


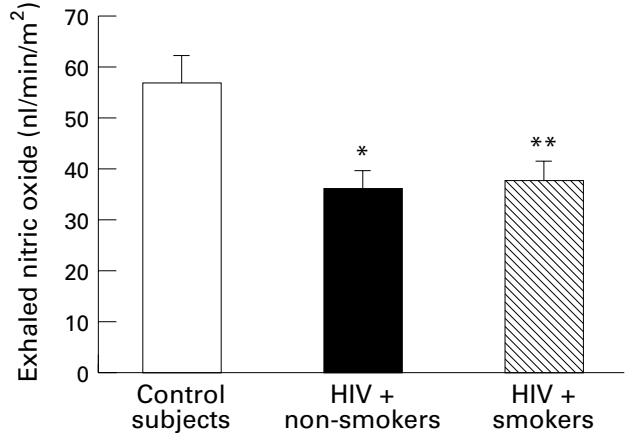

Figure 1 Exhaled nitric oxide from healthy control subjects and HIV positive subjects (non-smokers and smokers) recruited from an outpatient HIV clinic. Levels of exhaled NO from both HIV positive smokers and nonsmokers were lower than those from control subjects (control versus non-smokers, $p<0.008$; control versus smokers, $p<0.03)$. There was no difference between exhaled NO values for HIV positive smokers and nonsmokers.

defining opportunistic infection. There was no relation (linear regression, $r=0.04$ ) between exhaled NO and the most recent CD4 lymphocyte counts.

\section{Discussion}

There is reason to suspect that endogenous NO production in the respiratory tract may be reduced in HIV infected subjects. Nitric oxide may participate in the immune response against viral, bacterial, fungal, and protozoal infections, and against tumours, ${ }^{1}$ all of which occur with increased frequency in HIV infected individuals. In addition, a syndrome very similar to primary pulmonary hypertension occurs in HIV infection. ${ }^{8}$ Since endogenous NO may be reduced in some types of pulmonary hypertension, ${ }^{9}$ it is possible that reduced endogenous NO plays a role in the pulmonary hypertension of HIV infection.

Endogenously produced $\mathrm{NO}$ is present in the exhaled air of normal humans. ${ }^{2}$ Both the upper and lower respiratory tracts release NO. ${ }^{10}$ Exhaled NO is increased in patients with diseases associated with respiratory tract inflammation such as asthma, ${ }^{34}$ bronchiectasis, ${ }^{5}$ and viral infections. ${ }^{6}$ In contrast, exhaled NO is reduced by corticosteroid therapy in asthmatic subjects $^{7}$ and by cigarette smoking. ${ }^{3}$ The latter may be due to high levels of NO in cigarette smoke which downregulate NO synthase. Although the relationship between exhaled NO and total respiratory tract $\mathrm{NO}$ production is not known, the suggestion has been made that exhaled NO may be a monitor of respiratory tract inflammation. ${ }^{4}$

Our results show that exhaled $\mathrm{NO}$ is reduced in HIV infection. The effect of smoking did not account for our findings since exhaled $\mathrm{NO}$ was reduced in both smoking and non-smoking HIV positive subjects. The lack of correlation between decreased exhaled $\mathrm{NO}$ and $\mathrm{CD} 4$ lymphocyte counts in HIV infected subjects suggests that reduced NO is not simply a function of the numbers of these immune effector cells. Our findings are consistent with the hypothesis that individuals with HIV infection have reduced endogenous $\mathrm{NO}$ in the respiratory tract. The causes could be multifactorial and be due to either reduced constitutive or inducible NO synthase function from progressive immunological deactivation or other mechanisms. If this hypothesis is correct, reduced endogenous NO may represent a host defence defect in HIV infection.

The authors gratefully acknowledgement the helpful assistance of Drs Melanie Scurry and Sally Williams.

1 Moncada S, Palmer RMJ, Higgs EA. Nitric oxide: physiology, pathophysiology, and pharmacology. Pharmacol Rev 1991;43:109-42.

2 Gustafson LE, Leone AM, Perrson MG, Wiklund NP Moncada S. Endogenous nitric oxide is present in the Moncada S. Endogenous nitric oxide is present in the Biophys Res Commun 1991;181:852-7.

3 Persson MG, Zetterstrom O, Agrenius V, Ihre E, Gustafsson LE. Single-breath nitric oxide measurements in asthmatic patients and smokers. Lancet 1994;343:146-7.

4 Kharitonov SA, Yates D, Robbins RA, Logan-Sinclair R, Shinebourne EA, Barnes PJ. Increased nitric oxide in exhaled air of asthmatic patients. Lancet 1994;343:133-5.

5 Kharitonov SA, Wells AU, O'Connor BJ, Hansell D, Cole PJ, Barnes PJ. Elevated levels of exhaled nitric oxide in bronchiectasis. Am F Respir Crit Care Med 1995;151 1889-93.

6 Kharitonov SA, Yates D, Barnes PJ. Increased nitric oxide in exhaled air of normal subjects with upper respiratory tract infections. Eur Respir f 1995;8:2957.

7 Yates DH, Kharitonov SA, Robbins RA, Thomas PS, Barnes PJ. Effect of a nitric oxide synthase inhibitor and a glucocorticoid on exhaled nitric oxide. Am $\mathcal{F}$ Respir Crit Care Med 1995;152:892-6.

8 Petipretz P, Brenot F, Azarian R, Parent F, Rain B, Herve $\mathrm{P}$, et al. Pulmonary hypertension in patients with human immunodeficiency virus infection. Comparison with primimmunodeficiency virus infection. Comparison with prim-

9 Dinh-Xuan AT, Higenbottom TW, Clelland CA, PepkeZaba J, Cremona G, Yazdani-Butt A, et al. Impairment of endothelium-dependent pulmonary artery relaxation in chronic obstructive pulmonary disease. $N \mathrm{Engl} \mathrm{f} \mathrm{Med}$ 1991;324:1539-47.

10 Gerlach H, Rossaint R, Pappert D, Knorr M, Falke KJ. Autoinhalation of nitric oxide after endogenous synthesis in nasopharynx. Lancet 1994;343:518-9. 